\title{
Habitat-dependent recruitment of two temperate reef fishes at multiple spatial scales
}

\author{
Kelly S. Andrews ${ }^{1,2, *}$, Todd W. Anderson ${ }^{1}$ \\ ${ }^{1}$ Department of Biology, San Diego State University, San Diego, California 92182-4614, USA \\ ${ }^{2}$ Present address: NOAA Fisheries, 2725 Montlake Boulevard East, Seattle, Washington 98112, USA
}

\begin{abstract}
The distribution and abundance of reef fishes has often been attributed to several processes that result in some measure of recruitment success (settlement and survival of young individuals). We employed a large-scale experimental rocky reef system to examine patterns of recruitment of 2 fishes, the California sheephead Semicossyphus pulcher and the blackeye goby Rhinogobiops nicholsii. We quantified recruitment over a 2 yr period on 21 experimental reefs (each $1600 \mathrm{~m}^{2}$ ) that represented low, medium, and high treatments of habitat coverage. Recruitment of California sheephead was higher on reefs of medium habitat coverage than on reefs with other coverages, while the blackeye goby exhibited lower recruitment on reefs of low coverage than on reefs with other coverages. Within reefs, recruitment to 'edge' habitat was lower than 'inside' the reef for each species. At the smallest scale, several measures of habitat structure were quantified within $1 \mathrm{~m}^{2}$ quadrats to identify microhabitat characteristics that might explain the distribution of recruits. Rugosity was an important characteristic for predicting the presence of recruits for each species at this small scale. The densities of recruits of California sheephead among treatments of habitat corresponded to the densities of Age 1+ (individuals which recruited during the previous year) california sheephead among treatments the following year, suggesting that spatial patterns of abundance may be established early in life. The abundance of predators did not appear to influence the patterns of recruitment observed for either species. Low densities of recruits for each species may have led to the patterns of recruitment observed through the processes of habitat selection at settlement and densityindependent mortality. Longer temporal studies covering variable recruitment are needed to determine the importance of habitat structure relative to other processes.
\end{abstract}

KEY WORDS: Recruitment · Habitat - California sheephead · Blackeye goby

\section{INTRODUCTION}

The distribution and abundance of organisms depends to some extent on spatial variation in the physical structure of available habitat (Bell et al. 1991, Rotenberry \& Wiens 1998). Variation in habitat structure to which organisms may respond exists at several spatial scales (Maurer 1985, MacFaden \& Capen 2002, Williams et al. 2002), and our detection and interpretation of relationships is dependent upon the scale measured (Sherry \& Holmes 1985, Caselle \& Warner 1996). Consequently, studies of relationships between habitat and the distribution and abundance of target species should be done at appropriate scales, often leading to studies performed at multiple scales (Weins 1985, 1989, Sale 1991).
Habitat structure is important in predicting the abundance and distribution of many taxa, including birds (MacArthur \& MacArthur 1961, Brown \& Stillman 1993), lizards (Pianka 1966, Reagan 1991), and invertebrates (Nelson 1979, Beck 1998). Such relationships are particularly evident in the early life stages of reef fishes in that recently settled (settlement defined as the immediate transition from a pelagic larval stage to a benthic juvenile stage; Keough \& Downes 1982) individuals often appear to select complex habitats (Roberts \& Ormond 1987, Tupper \& Boutilier 1997). Young fish may occupy specific depths (Jones 1997), habitats containing conspecifics or congeners (Sweatman 1985, Booth 1992, Steele 1997a), and biogenic structures such as macroalgae or coral (Carr 1991, 
1994a, Levin 1991, Tolimieri 1998). Recruitment (the number of new individuals in local populations that have survived to some arbitrary point in time after settlement) of these early life stages has been identified as a time at which the abundance of populations of reef fishes are determined by pre-settlement processes occurring during the pelagic phase (Doherty 1981, Victor 1983, Doherty \& Fowler 1994), by subsequent post-settlement processes (Hixon \& Carr 1997, Steele 1997b, Carr et al. 2002), or probably by a combination of both (Jones 1991, Caley et al. 1996). The prevalence of correlations between the abundance of recruits and specific habitat features suggests that the abundance and distribution of recently settled reef fishes are habitat-dependent (Carr 1991, 1994a, Levin 1991, Tolimieri 1995, Steele 1999, Holbrook et al. 2000). Moreover, correspondence between the density of recruits and the density of older individuals in the following year (Carr 1994a), and microhabitat preferences of recently settled recruits that may explain local patterns of adult distribution (Gutierrez 1998) suggest that patterns of habitat-dependent recruitment may influence the patterns of abundance of older individuals. Therefore, understanding how habitat contributes to variation in recruitment is important in describing the overall dynamics of local populations of reef fishes.

Spatial and temporal variation in recruitment may be caused by the supply of larvae transported to a location (Doherty 1981, Victor 1983, Cowen 1985, Milicich et al. 1992, Meekan et al. 1993), larval behavior during settlement (Sweatman 1985, Holbrook \& Schmitt 1997), early post-settlement processes, such as predatorinduced mortality (Hixon \& Carr 1997, Steele 1997b, Schmitt \& Holbrook 1999, Carr et al. 2002), or postsettlement migration. Sources of variation in recruitment can be modified further by particular habitat features. At a very large scale, coastline configuration or bottom topography of the ocean may have a significant influence on currents and eddies that transport larvae to local sites (Cowen 2002). At the scale of individual reefs, the 'edge' and the 'inside' of a reef may affect the abundance of reef fish populations differently, analogous to the effects that habitat fragmentation has been shown to have in many terrestrial populations (e.g. Temple 1986, Paton 1994, Tewksbury et al. 1998). The distribution of newly settled fishes among different types of habitat within a reef may result from food availability (Levin 1994, but see Levin et al. 1997), the distribution of predators (Hixon 1991), or the location at which settlement has occurred (i.e. settlement on first available habitat: Jones 1997). It is largely unknown whether recruitment of reef fishes differs substantially between the edge and the inside of reefs; however, juvenile señorita Oxyjulis californica have been found at higher densities on the ecotone of artificial reefs (Anderson et al. 1989), recruitment of some rockfishes occur at the edges of rocky reefs (Carr 1991), and the densities of adult black rockfish Sebastes melanops are highest at the edges of kelp beds of Nereocystis luetkeana (Leaman 1976).

The abundance and distribution of recruits of reef fishes often exhibit strong relationships with specific characteristics of the habitat, such as coral cover (Tolimieri 1998, Schmitt \& Holbrook 2000), the presence and density of macroalgae (Carr 1991, 1994a,b, Levin 1991, 1993) or rock (Steele 1999), and substratum rugosity (Tupper \& Boutilier 1997). Furthermore, predator-induced mortality may be mediated by the presence of habitats that provide physical refuges (Hixon \& Beets 1993, Nemeth 1998, Steele 1999) or reduce the efficiency of some predators (Beukers \& Jones 1997), resulting in lower mortality rates.

In contrast, other studies have shown no relationship between habitat characteristics and the density of recruits (Levin 1994, Petrik et al. 1999) or no interaction between habitat complexity and predator foraging success in patterns of post-settlement mortality (Almany 2004). Interestingly, characteristics of microhabitats that may predict the density of new recruits at small spatial scales do not necessarily predict such densities at larger spatial scales (Tolimieri 1995, Caselle \& Warner 1996, Levin et al. 1997). These contrasting results suggest that the influence of habitat characteristics on the recruitment of reef fishes varies widely and that the lack of correspondence in habitatdependent recruitment between small and large spatial scales requires further investigation.

Using a large experimental reef system, we investigated the relationship between habitat characteristics and recruitment of reef fishes at multiple spatial scales. The large spatial scale of this experimental reef system is unprecedented, and it allowed the investigation of relationships between reef fishes and habitat at a scale beyond that of most experimental studies. We used the California sheephead Semicossyphus pulcher and the blackeye goby Rhinogobiops nicholsii as model species for habitat-dependent recruitment. The California sheephead is commercially and recreationally important in southern California, and so any information on variability in demography is important. Moreover, settlement of the California sheephead occurs during the fall (Cowen 1985), when underwater visibility is predictably better. The blackeye goby is a strongly siteattached species (Steele 1995) that is numerically abundant on many rocky subtidal reefs, thus providing a good model for examining the population dynamics of reef fishes (Steele 1997a,b, 1998, 1999, Steele et. al 1998, Forrester \& Steele 2000). Specifically, we asked 4 questions: (1) Does recruitment vary among reefs with different coverages of rocky-reef habitat and does the 
pattern of recruitment remain consistent within and between years? (2) Does the abundance of recruits correspond to the abundance of older individuals in a cohort over time? (3) Does recruitment vary between the 'inside' and 'edge' of reefs? (4) Are there specific microhabitat characteristics that explain the distribution of recruits within reefs, and do such relationships hold true at larger spatial scales?

\section{MATERIALS AND METHODS}

Target species. The California sheephead is a protogynous hermaphrodite (Wiley 1973, Warner 1975), common to temperate rocky reefs in southern California, with a range extending from Point Conception, California, in the north to Isla Santa Margarita, Baja California, Mexico, in the south (Cowen 1985). The California sheephead spawns several times between August and October (Warner 1975). Larvae are planktonic for $\sim 60 \mathrm{~d}$ before they settle to the benthic habitat at $\sim 13$ to $16 \mathrm{~mm}$ standard length (SL) (Cowen 1991). Recently settled individuals have a conspicuous color pattern (reddish-orange body with a medial, white horizontal stripe, distinct black spot on the pelvic and anal fins, 2 spots on the dorsal fin, and 1 at the base of the caudal fin) that persists through the first year of life. This species feeds primarily upon benthic invertebrates.

The blackeye goby is also a protogynous hermaphrodite common to southern California rocky reefs, with a range extending from Queen Charlotte Island, British Columbia, to Point Rompiente, Baja California, Mexico (Miller \& Lea 1972). Females lay demersal eggs that are guarded by males (Wiley 1973). Upon hatching, larvae spend 2 to $3 \mathrm{mo}$ in the plankton before settling at $\sim 15$ to $25 \mathrm{~mm}$ SL to the benthic habitat, with settlement peaks in June and July in southern California (M. Steele unpubl. data). This species feeds upon benthic invertebrates and zooplankton (Wiley 1973). The blackeye goby displays site-fidelity and is numerically abundant on many rocky reefs.

Experimental system. The California Coastal Commission required Southern California Edison to construct an artificial reef large enough to replace a minimum of 60.7 ha of kelp habitat as mitigation for losses of kelp-bed resources caused by operation of the San Onofre Nuclear Generating Station. A 5 yr experimental phase, beginning in 1999, provided a unique opportunity to conduct research at a large experimental rocky reef system. The system was deployed $\sim 2 \mathrm{~km}$ offshore of the coast near San Clemente, California, at $\sim 15 \mathrm{~m}$ depth, spanning a distance of $3.3 \mathrm{~km}$ along the coastline. Seven replicate rocky reef modules (hereafter 'reefs') of 8 different designs were deployed in a completely randomized block design consisting of 2 types of bottom substratum (quarry rock and recycled concrete), 3 levels of hard substratum coverage (low, medium, and high), and 2 levels of kelp abundance (with and without transplanted kelp on medium substratum coverage), totaling 56 reefs, each reef being 0.16 ha $(40 \times 40 \mathrm{~m})$ in size (Fig. 1a). We focused our research on quarry rock reefs without transplanted kelp, using 7 replicates for each of the 3 levels of coverage of rocky reef habitat (Fig. 1a). These reefs were those most similar to the low-relief cobble bottom substratum found naturally along this coastline. The 3 levels of habitat coverage reflected the following percentage cover of quarry rock among treatments (mean $\pm \mathrm{SE}$ ): low $=36 \pm 2.5 \%$, medium $=64 \pm 2.0 \%$, and high $=81 \pm 1.4 \%$ (Fig. $1 \mathrm{~b}$ ).

Patterns of recruitment among reefs. Variation in early recruitment (our best estimate of initial input to

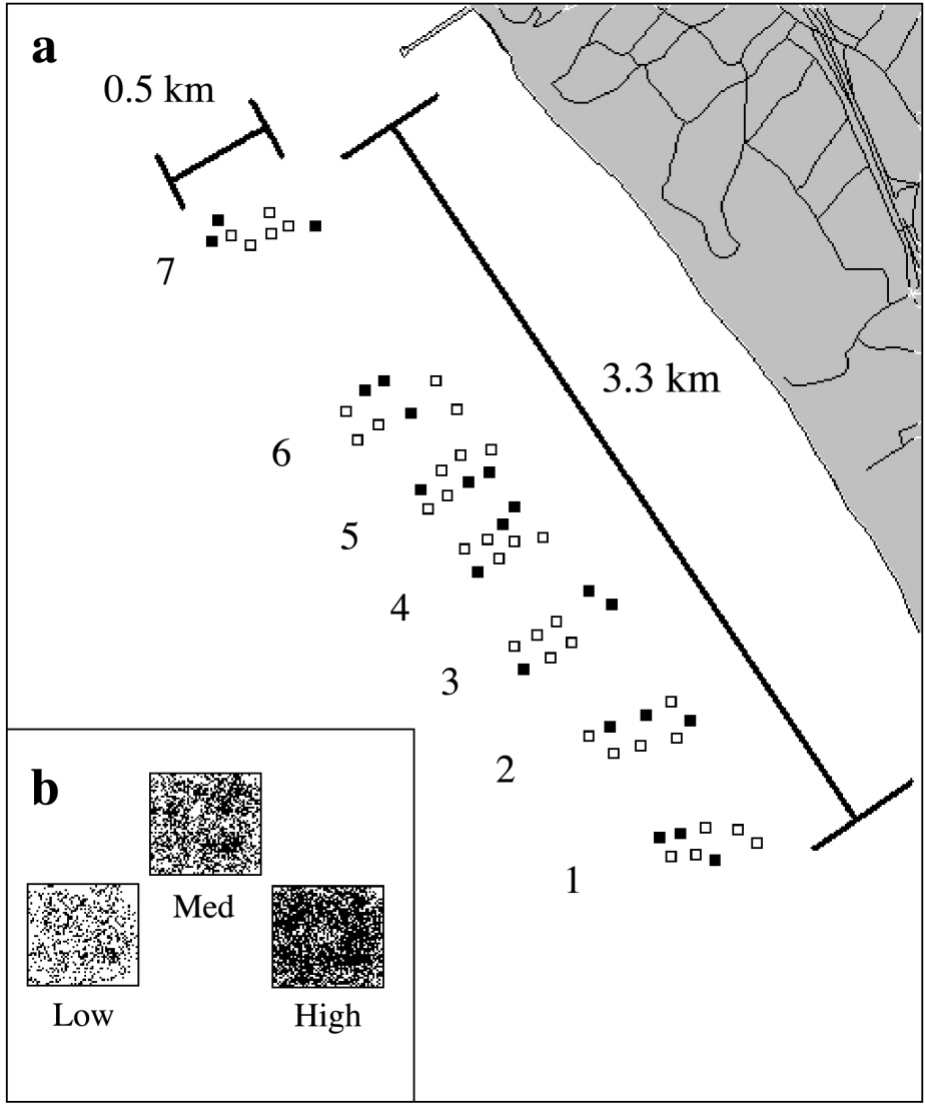

Fig. 1. (a) Experimental reef system near San Clemente, California; ( 21 reefs used in present study. (b) Habitat coverage (low, medium, high) for 3 reefs in each of 7 blocks 
the local population) and recruitment success (our best estimate of end-of-year densities that accounts for both larval settlement and post-settlement processes) among the coverages of quarry rock was examined using 2 visual surveys of 21 experimental reefs: (1) October 18 to November 2, 2001 (hereafter October 2001 survey), (2) December 17, 2001 to January 21, 2002 (hereafter December 2001 survey). In the December 2001 survey, only 6 blocks (18 reefs) were sampled due to constraints in underwater visibility. Because there were no differences in patterns of early recruitment and recruitment success among the coverages of habitat in 2001 (see 'Results'), a single survey of the same 21 experimental reefs was conducted to determine patterns of recruitment success in 2002: November 17, 2002 to February 7, 2003 (hereafter November 2002 survey). Surveys began in the fall, when underwater visibility was predictably better and when settlement of California sheephead had begun. Although the blackeye goby probably settles year-round, with peaks in June and July, poor underwater visibility did not allow us to perform surveys during these peak settlement periods. For all completed surveys, visibilities of at least $2.5 \mathrm{~m}$ were required. The 3 reefs within each block were sampled on the same day to avoid temporal variation in visibility or other environmental conditions among blocks.

Each survey was performed with SCUBA by swimming 4 fixed transect lines along the bottom at distances of 5, 15, 25 and $35 \mathrm{~m}$ from the northwest corner of each reef. Along each transect line, young-of-year recruits (California sheephead $<8 \mathrm{~cm}$ TL and blackeye goby $<5 \mathrm{~cm}$ TL) along with their major predators (the kelp bass Paralabrax clathratus and the barred sand bass $P$. nebulifer $>15 \mathrm{~cm}$ TL) were counted, with their size being estimated visually. In the November 2002 survey, Age 1+ California sheephead (10 to $14 \mathrm{~cm} \mathrm{TL)}$ were distinguishable by coloration (e.g. black spots on fins still present) and counted. Transect dimensions were $2 \mathrm{~m}$ wide $\times 2 \mathrm{~m}$ high $\times 40 \mathrm{~m}$ long for censusing California sheephead and all predators. Blackeye gobies were censused after the California sheephead and all predators while swimming back along the same fixed transect lines although the width of the transect was reduced to $1 \mathrm{~m}$ because blackeye goby were more cryptic than California sheephead. An additional 2 transects $(2 \mathrm{~m}$ wide $\times 2 \mathrm{~m}$ high $\times 40 \mathrm{~m}$ long) were censused in midwater ( $7 \mathrm{~m}$ depth) and in the kelp (Macrocystis pyrifera) canopy ( $2 \mathrm{~m}$ depth) to estimate predator densities on each reef. Each transect took approximately 5 min to swim by 2 experienced divers and was conducted at approximately the same time each day (between 09:00 and 15:00 h).

Densities of recruits of the California sheephead and the blackeye goby (ind. $100 \mathrm{~m}^{-3}$ and ind. $100 \mathrm{~m}^{-2}$, respectively) were calculated from counts recorded at each reef. All densities for recruits of both species and Age 1+ California sheephead were transformed $[\sqrt{(x+0.375)}]$ to meet the statistical assumption of homogeneity of variances (Zar 1999). Because Block 7 (see Fig. 1) was not censused in December 2001, all reefs in that block were excluded from further analyses. All statistical analyses were performed using SYSTAT Version 10.0 (SYSTAT 2000).

Variation in recruitment across habitat-coverage treatments in 2001 was examined for each species using repeated-measures ANOVA. Transformed densities of recruits in October 2001 and in December 2001 were the dependent variables, with block and percentage cover of habitat as the independent variables. Significant effects $(p<0.05)$ were examined using Tukey's honest significant difference (HSD) post hoc multiple-comparison test. Recruitment success (densities of the California sheephead and the blackeye goby in late fall) across habitat-coverage treatments and between years was examined for each species with a 3-factor ANOVA. The transformed density of recruits was the dependent variable, with year, habitat coverage and block as independent variables. Because recruitment between years constitutes the influx of new individuals to the experimental system, and because there was no simple linear correlation between the relative magnitude of recruitment of the blackeye goby to the 6 blocks used in the analysis in one year versus the next $(r=0.35, n=6, p=0.49)$, we concluded that using 'year' as a variable in our model did not violate statistical independence. Recruitment failure of the California sheephead (see 'Results') did not present a meaningful test for a correlation in this species. Significant effects $(p<0.05)$ were examined using Tukey's HSD multiple-comparison test.

To determine if the densities of young California sheephead across habitat-coverage treatments corresponded over time with those of older individuals of the same cohort, we performed a repeated-measures ANOVA including densities of fishes from the October 2001, December 2001, and November 2002 surveys. The same analysis was not conducted for the blackeye goby because a specific cohort was not distinguishable, presumably because of protracted recruitment throughout the same period.

Patterns of recruitment within reefs. 'Edge' and 'inside' habitats: To determine whether new recruits of the California sheephead or the blackeye goby occurred in different densities along the edge or inside of a reef, we conducted additional transects of the same aforementioned dimensions along the ecotone (rock/ sand interface on the perimeter of a reef). We conducted 2 transects for each species on the north and west sides of each reef to estimate recruitment at 
the ecotone during surveys in December 2001 and November 2002.

All fishes were counted, and densities calculated and transformed as above. A paired $t$-test between densities at the edge and inside of the reef was done for each species in 2001 to determine if there were differences between the 2 types of habitat.

Microhabitat associations: At the smallest spatial scale, we determined whether the California sheephead or the blackeye goby exhibited preferences for specific microhabitats. On each of the 21 quarry-rock reefs, we measured or estimated several microhabitat characteristics for $1 \mathrm{~m}^{2}$ quadrats placed directly below recruits of each species found during haphazard searches and for $1 \mathrm{~m}^{2}$ quadrats placed at random points on each reef.

The characteristics measured were rugosity, vertical relief and percentage cover of rock, sand, mudstone (natural hard substratum) and algae (red and brown macroalgae were measured; crustose coralline algae were not measured). Rugosity was measured by laying a 12-gauge bronze-linked chain along the contour of the bottom from one side of the quadrat to the other. We took 2 measurements perpendicular to each other, each bisecting the quadrat, and then summed these and divided the result by the total linear distance to calculate an index of rugosity per quadrat (Risk 1972, Friedlander \& Parrish 1998). Vertical relief was measured as the distance from the lowest point to the highest point of the rocky reef habitat within each quadrat.

Percentage cover estimates of rock, sand, mudstone and algae were made visually, a method which Dethier et al. (1993) found provided an estimate of percentage cover as accurate as a random-point contact method. To validate our visual estimates, we performed an initial experiment to compare the 2 methods. Visual estimates of percentage cover of rock, sand, mudstone and algae were recorded within a quadrat, followed by dividing the quadrat into equal size squares using 25 equally spaced points and scoring the substratum type for each point. The percentage of the total points for each substratum type was compared to visual percentage estimates of cover using a paired $t$-test. There was no significant difference between the 2 estimates of percentage cover for any of the variables measured (rock: $t=-0.228, \mathrm{p}=0.82$; sand: $t=0.327, \mathrm{p}=0.744$; mudstone: $t=-0.295, \mathrm{p}=0.770$; algae: $t=0.193$, $\mathrm{p}=0.848 ; \mathrm{n}=69$ for all variables).

Percentage cover estimates were transformed (arcsine $\sqrt{x}$ ) to satisfy assumptions of a normal distribution, and vertical relief was transformed $\left(x^{2}\right)$ to meet the assumption of homogeneity of variances. Analyses of the transformed data for all microhabitat characteristics measured showed that they were significantly correlated. To use these characteristics as predictor variables in multiple logistic regression analyses, correlations were removed using the methods of Graham (1997). Multiple logistic regression (in this case used to estimate the probability of presence of a species) was used instead of multiple regression (used to estimate how much of the variation in the density of each species could be explained by particular variables) because of the very low densities of recruits found on reefs for both species. The residuals (non-correlated parts) of the pair-wise linear regressions for each combination of characteristics were retained for further analyses. Based on preliminary examinations of habitat characteristics and indications from other studies that rugosity is a relevant measure of habitat complexity (e.g. Tupper \& Boutilier 1997, Friedlander \& Parrish 1998), this was the first independent variable entered into the model, against which every other independent variable was regressed in the procedure. This procedure resulted in rugosity and 5 new variables: vertical relief residuals, rock residuals, sand residuals, mudstone residuals and algae residuals. These 6 variables were used as predictor variables in a multiple logistic regression model in which the presence or absence of a recruit was the dependent variable. Backward stepwise procedures were used to determine the model with the best fit. Predictor variables were eliminated at each step if they did not contribute significantly $(p>0.15)$ to the model during each iterative step. Probability plots of the presence or absence for each species were made for significant predictor variables $(p<0.05)$ using the logistic regression function

$$
[P]=\exp \left(B_{0}+B_{\mathrm{i}} X\right) /\left(1+\exp \left(B_{0}+B_{\mathrm{i}} X\right)\right)
$$

where $[P]$ is the probability of recruit presence, $B_{0}$ is the constant coefficient, $B_{1}$ is the variable's coefficient, and $X$ is a range of values of the significant predictor variable (see Chatterjee et al. 2000).

\section{RESULTS}

\section{Patterns of recruitment among reefs}

Patterns of early recruitment and recruitment success among habitat-coverage treatments in 2001 showed similar results for both species: a hump-shaped distribution, with medium coverage exhibiting higher densities of recruits in 2001 (Fig. 2). A significant effect of habitat coverage and a non-significant survey $\times$ habitat interaction (Table 1) for both species indicated that patterns of recruitment were different among coverages of habitat and that these patterns remained consistent within the period of recruitment. The density of recruits of California sheephead was higher for medium habitat-coverage than for both low and high 

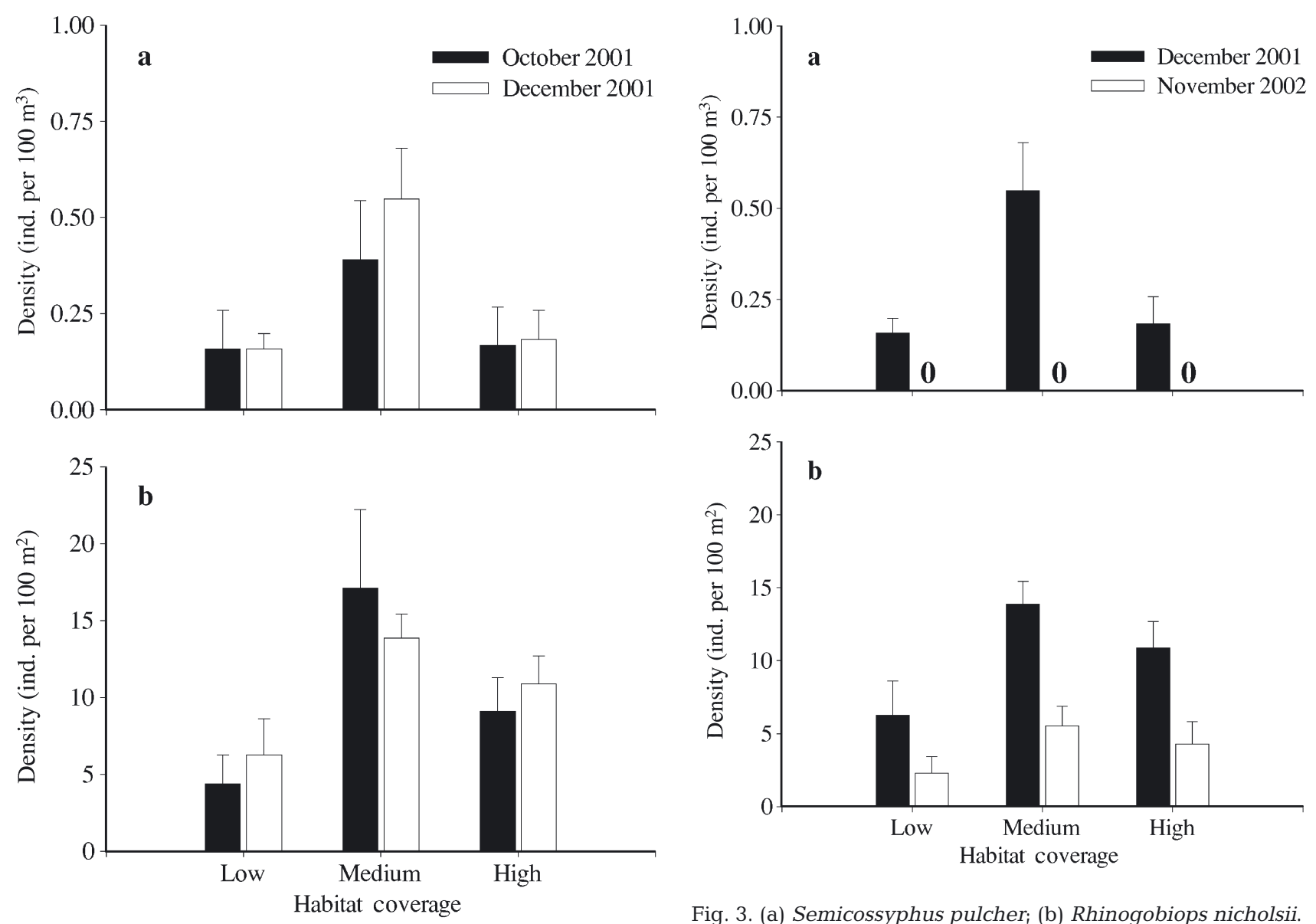

Fig. 2. (a) Semicossyphus pulcher; (b) Rhinogobiops nicholsii. Densities of recruits (mean + SE) in low-, medium- and highcoverage treatments of habitat for 2 surveys in fall 2001; $\mathrm{n}=6$ reefs for each bar

Fig. 3. (a) Semicossyphus pulcher; (b) Rhinogobiops nicholsii. Recruitment success of recruits (mean + SE) in late fall 2001 and 2002 in low, medium and high habitat-coverage treatments; $\mathrm{n}=6$ reefs for each bar. Zero values indicate that no recruits of California sheephead were recorded on reefs in 2002

coverage (Tukey's HSD, $\mathrm{p}<0.025)$. There was no difference between low and high coverage (Tukey's HSD, $p>0.50$ ). For the blackeye goby, the density of recruits was lower for low habitat-coverage than for medium

Table 1. Semicossyphus pulcher and Rhinogobiops nicholsii. Repeated measures ANOVA of square root $(x+0.375)$-transformed densities of recruits of California sheephead and blackeye goby from surveys in October 2001 and December 2001

\begin{tabular}{|lrrrrrrrr|}
\hline \multirow{2}{*}{ Source } & df & \multicolumn{3}{c}{ California sheephead } & \multicolumn{3}{c|}{ Blackeye goby } \\
& & MS & $F$ & $p$ & & MS & $F$ & $p$ \\
\hline Between subjects & & & & & & & \\
$\quad$ Habitat & 2 & 0.12 & 4.88 & 0.033 & 8.99 & 7.57 & 0.010 \\
Block & 5 & 0.07 & 2.75 & 0.082 & 2.02 & 1.70 & 0.221 \\
$\quad$ Error & 10 & 0.03 & & & 1.19 & & \\
Within subjects & & & & & & & \\
$\quad$ Survey & 1 & 0.01 & 2.58 & 0.140 & 0.17 & 0.83 & 0.384 \\
$\quad$ Survey $\times$ Habitat & 2 & 0.01 & 1.12 & 0.365 & 0.36 & 1.73 & 0.226 \\
$\quad$ Survey $\times$ Block & 5 & 0.01 & 2.35 & 0.117 & 0.74 & 3.52 & 0.043 \\
$\quad$ Error & 10 & 0.01 & & & 0.21 & & \\
\hline
\end{tabular}

(Tukey's HSD, p < 0.005) and high (Tukey's HSD, $\mathrm{p}=0.05)$ coverage, and there was no difference between medium and high coverage (Tukey's HSD, $p>0.10$ ). The density of recruits among blocks was highly variable and did not differ significantly for either species across the experimental reef system.

Recruitment success (December 2001 and November 2002 surveys) for each species among habitat-coverage treatments also exhibited a hump-shaped distribution, with the highest densities for medium coverage of habitat over the 2 years (Fig. 3). Most apparent, however, was the total recruitment failure of California sheephead in 2002. Recruits were never observed on any reefs from October 2002 to February 2003. Consequently, there was a significant year $\times$ habitat interaction for California sheephead 
Table 2. Semicossyphus pulcher and Rhinogobiops nicholsii. ANOVA of square root $(x+0.375)$-transformed densities of recruits of California sheephead and blackeye goby between years (December 2001 and November 2002)

\begin{tabular}{|lcccccccc|}
\hline \multirow{2}{*}{ Source } & df & \multicolumn{3}{c}{ California sheephead } & \multicolumn{3}{c|}{ Blackeye goby } \\
& & MS & $F$ & $p$ & MS & $F$ & $p$ \\
\hline Year & 1 & 0.34 & 55.11 & $<0.001$ & 10.96 & $23.63<0.001$ \\
Habitat & 2 & 0.05 & 7.49 & 0.004 & 3.86 & 8.32 & 0.002 \\
Block & 5 & 0.02 & 2.49 & 0.066 & 1.58 & 3.40 & 0.022 \\
Year $\times$ Habitat & 2 & 0.05 & 7.49 & 0.004 & 0.22 & 0.47 & 0.63 \\
Year $\times$ Block & 5 & 0.02 & 2.49 & 0.066 & 0.77 & 1.65 & 0.193 \\
Error & 20 & 0.01 & & & 0.46 & & \\
& & & & & & & & \\
\hline
\end{tabular}

(Table 2). However, differences in recruitment of California sheephead among habitat-coverage treatments in 2001 clearly demonstrated a significant effect of habitat. For the blackeye goby, recruitment success for the years 2001 and 2002 was significantly lower for low habitat-coverage than for medium (Tukey's HSD, p = 0.002) and high (Tukey's HSD, p = 0.023) coverage, but there was no significant difference between medium and high coverage (Tukey's HSD, $\mathrm{p}=0.57$ ). The significant block effect for blackeye goby is not noteworthy as it is the
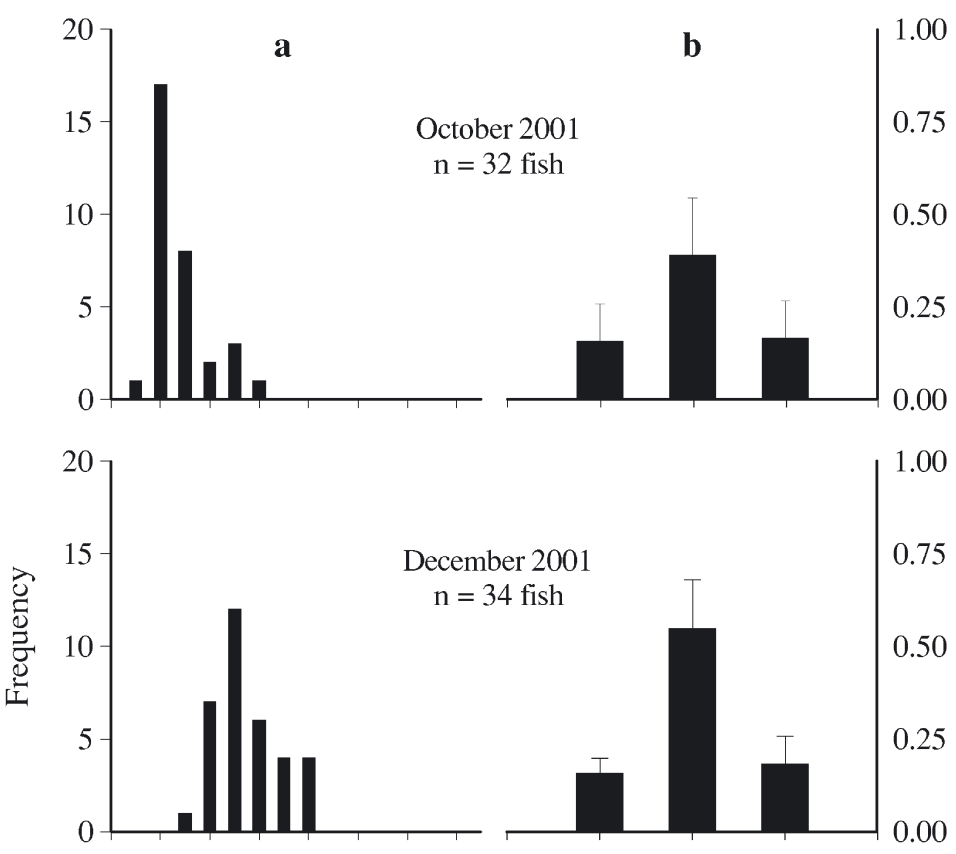

0.75

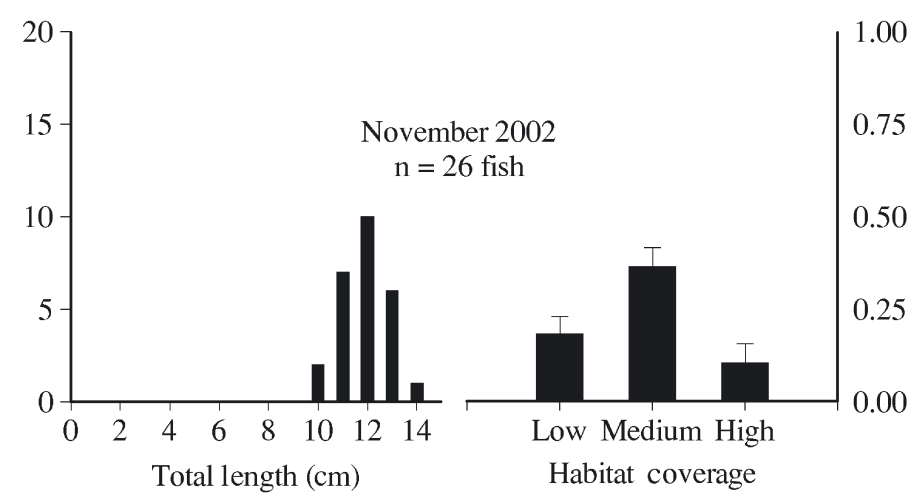

Fig. 4. Semicossyphus pulcher. a: Size-frequency distribution of individuals on all habitat coverages combined; b: densities (mean $+\mathrm{SE}$ ) in low, medium and high habitat-coverage treatments for each survey of a single cohort. October 2001: early recruitment; December 2001: recruitment success; November 2002: Age 1+ individuals; $\mathrm{n}=6$ reefs for each density bar result of differences only between Blocks 2 and 4 (Fig. 1) (Tukey's HSD, p=0.042) and does not appear to represent any type of gradient in recruitment along the coastline.

A single cohort of California sheephead could be distinguished by size classes and was examined over the 3 surveys between 2001 and 2002 (Fig. 4a). The densities of young California sheephead in 2001 and older individuals (Age 1+) of that cohort in 2002 corresponded in their patterns among coverages of habitat during the 3 surveys (Fig. 4b). A significant effect of habitat and a non-significant survey $\times$ habitat interaction (Table 3) indicated that the patterns of density were different among coverages of habitat and that they remained consistent over more than a 1 yr period. Specifically, medium coverages of habitat had higher densities than did low (Tukey's HSD, p < 0.05) and high (Tukey's HSD, p = 0.025) coverage; there was no difference in the densities of recruits between low and high coverages of habitat (Tukey's HSD, $\mathrm{p}>0.50$ ).

The density and distribution of predators (the kelp bass Paralabrax clathratus and the barred sand bass $P$. nebulifer) were examined to determine whether predator density might explain differences in recruitment and should be included as covariates in analyses. There was a positive relationship between the densities of predators and recruits in October 2001 (California sheephead: $\mathrm{r}=0.438, \mathrm{p}=0.047$; blackeye goby: $r=0.518, p=0.016)$. There were no significant relationships between the densities of predators and recruits for either species in the December 2001 survey (California sheephead: $\mathrm{r}=0.036, \mathrm{p}=0.889$; blackeye goby: $r=0.394, p=0.106$ ) or for recruits of the blackeye goby in the November 2002 survey $(\mathrm{r}=0.245, \mathrm{p}=0.285)$. To determine whether 
Table 3. Semicossyphus pulcher. Repeated measures ANOVA of square root $(x+0.375)$-transformed densities of a single cohort of California sheephead from surveys in October 2001, December 2001 and November 2002. Greenhouse-Geiser (G-G) epsilon = 0.8963; Huynh-Feldt $(\mathrm{H}-\mathrm{F})$ epsilon $=1.0000$

\begin{tabular}{|lrccccc|}
\hline Source & df & MS & $F$ & $p$ & G-G & H-F \\
\hline Between subjects & & & & & & \\
$\quad$ Habitat & 2 & 0.16 & 6.24 & 0.017 & & \\
$\quad$ Block & 5 & 0.05 & 1.99 & 0.167 & & \\
$\quad$ Error & 10 & 0.03 & & & & \\
Within subjects & & & & & & \\
$\quad$ Survey & 2 & 0.01 & 1.63 & 0.221 & 0.224 & 0.221 \\
$\quad$ Survey $\times$ Habitat & 4 & 0.01 & 0.95 & 0.454 & 0.449 & 0.454 \\
$\quad$ Survey $\times$ Block & 10 & 0.02 & 2.89 & 0.021 & 0.021 & 0.021 \\
$\quad$ Error & 20 & 0.01 & & & & \\
\hline
\end{tabular}

changes in the density of recruits over time was related to the density of predators, correlations were performed using the difference in densities of recruits on reefs between the 2 surveys in 2001 and the mean density of predators for each reef during the 2001 surveys. Results were not significant for either the California sheephead $(r=0.410, p=0.091)$ or the blackeye goby $(\mathrm{r}=0.266, \mathrm{p}=0.287)$.

\section{Patterns of recruitment within reefs}

\section{'Edge' and 'inside' habitats}

Recruitment success was significantly higher inside reefs compared to the ecotone for both species in December 2001 (California sheephead: $t=5.004$, $\mathrm{df}=17, \mathrm{p}<0.001 ;$ blackeye goby: $t=2.69, \mathrm{df}=17$, $\mathrm{p}=0.016)$. Recruits of the California sheephead were never observed on the ecotone of any reef in these 2 years. In November 2002, recruitment failure for the California sheephead precluded analysis, but recruits of the blackeye goby were more abundant inside reefs compared to the ecotone $(t=3.631$, df $=14$, $\mathrm{p}=0.003$ ). The densities of predators (kelp bass and barred sand bass) averaged over the December 2001 and November 2002 surveys were also significantly higher 'inside' reefs when compared to the ecotone $(t=3.276, \mathrm{df}=11, \mathrm{p}=0.007)$.

\section{Microhabitat associations}

Mean values for each microhabitat characteristic showed, in general, that rugosity, vertical relief, and the percentage cover of rock were higher and percentage cover of sand lower in quadrats containing either species than in quadrats placed randomly (Table 4). Stepwise logistic regression resulted in significant models for each species in which the probability of the presence of a recruit was higher than by chance alone (Table 5: California sheephead: $\chi^{2}=22.022, \mathrm{df}=2$, $\mathrm{p}<0.001$; blackeye goby: $\chi^{2}=45.416$, df $=3, \mathrm{p}<$ $0.001)$. However, the amount of variation in the presence of recruits explained by the models was relatively low, as evidenced by the rho-squared values (Table 5).

Rugosity was a significant predictor of the presence of a recruit of the California sheephead (Table 5). The odds ratio for rugosity was $1.031(95 \% \mathrm{CI}=1.047$ to 1.015), which suggested that for every $1 \mathrm{~cm}$ increase in rugosity, the probability of a California sheephead being present increased by $3.1 \%$. Rugosity and sand residuals were significant predictors of the presence of a recruit of blackeye goby (Table 5). The odds ratio for rugosity was 1.030 (95\% CI = 1.041 to 1.019), which suggested that for every $1 \mathrm{~cm}$ increase in rugosity, the probability of a blackeye goby being present increased by $3.0 \%$. The odds ratio of sand residuals is difficult to interpret; the percentage cover of sand was lower in quadrats with the blackeye goby than in random quadrats.

Table 4. Mean ( \pm SE) values of microhabitat characteristics for quadrats with and without recruits of California sheephead Semicossyphus pulcher and blackeye goby Rhinogobiops nicolsii in treatments of low, medium (Med) and high habitat coverage. N: no. of quadrats; Rug: rugosity; VR: vertical relief

\begin{tabular}{|c|c|c|c|c|c|c|c|c|c|}
\hline \multirow[t]{2}{*}{ Variable } & \multicolumn{3}{|c|}{ California sheephead } & \multicolumn{3}{|c|}{ Random } & \multicolumn{3}{|c|}{ Blackeye goby } \\
\hline & Low & Med & High & Low & Med & High & Low & Med & High \\
\hline $\mathrm{N}$ & 7 & 22 & 8 & 57 & 57 & 55 & 60 & 69 & 67 \\
\hline Rock (\%) & $70(5)$ & $69(4)$ & $86(4)$ & $34(4)$ & $52(4)$ & $74(5)$ & $45(3)$ & $66(3)$ & $80(2)$ \\
\hline Sand (\%) & $21(7)$ & $31(4)$ & $14(4)$ & $51(5)$ & $43(4)$ & $23(4)$ & $28(3)$ & $29(2)$ & $18(2)$ \\
\hline Mud (\%) & $9(7)$ & 0 & 0 & $15(4)$ & $5(2)$ & $3(2)$ & $27(4)$ & $5(2)$ & 3 (1) \\
\hline Algae (\%) & $10(2)$ & $8(2)$ & $4(2)$ & $9(2)$ & $7(1)$ & $9(2)$ & $9(1)$ & $7(1)$ & $7(1)$ \\
\hline $\operatorname{Rug}(\mathrm{cm})$ & $160(6)$ & $152(6)$ & $156(7)$ & $126(3)$ & $133(3)$ & $148(4)$ & $141(2)$ & $150(3)$ & $156(3)$ \\
\hline VR $(\mathrm{cm})$ & $57(3)$ & $64(3)$ & $66(5)$ & $36(2)$ & $46(3)$ & $58(4)$ & $47(2)$ & $52(2)$ & $62(2)$ \\
\hline
\end{tabular}




\section{DISCUSSION}

Variation in the presence and amount of habitat often has been implicated in driving variation in the recruitment of reef fishes (e.g. Levin 1991, Anderson 1994, Carr 1994a, Tolimieri 1998, Schmitt \& Holbrook 2000). However, much of the supporting evidence has come from observational studies in which several habitat features are measured among sites and compared with the abundance and distribution of recruits. Such measurements can be confounded by the inherent habitat heterogeneity usually found among sites and within reefs. Experimental studies can control for habitat heterogeneity by standardizing habitat structure, but these studies are conducted typically at scales of only a few meters (but see Carr 1994a). The experimental reef system used in the present study addressed many of the concerns of previous observational and experimental studies: (1) the type, size, and quantity of bottom substratum were standardized among replicated treatments of habitat structure; (2) treatments were arranged over a large spatial scale; (3) each experimental unit covered a sizeable area $\left(1600 \mathrm{~m}^{2}\right)$. Thus, this extensive reef system allowed us the opportunity to study fish-habitat associations experimentally and at an unprecedented spatial scale. Moreover, the large size of each experimental unit allowed the study of species that generally exhibit sparse recruitment. The study of such species over typically much smaller experimental units would probably result in the absence of recruits in many instances, obscuring patterns and processes that may be observed at larger spatial scales.

\section{Patterns of recruitment}

We have shown that recruitment of the California sheephead was higher on reefs with intermediate coverage of habitat (defined as rocky reef substratum in the form of quarry rock on these experimental reefs) while the blackeye goby had similarly higher recruitment to reefs with both intermediate and high coverage of habitat. Recruitment of the California sheephead is related to larval dispersal on a large spatial scale (Cowen 1985), and this is the first study to our knowledge to examine the relationship between habitat and recruitment for this species. Recruitment of the blackeye goby increases with the amount of habitat in the form of rocky substratum at a small scale (Steele 1999), and our results generally support this previous work.
We know of no examples in which recruitment of fishes exhibits a hump-shaped pattern with increasing amounts of habitat, as we found in this study on the California sheephead. However, Jones \& Syms (1995) described a similar pattern for densities of adults of a confamilial species (the wrasse Gomphosus varius) and percentage cover of live coral. Several possible relationships may exist between recruitment of reef fishes and habitat. Carr (1994b) notes 3 different relationships between recruitment and the density of macroalgae using temperate kelp-associated reef fishes. Each relationship - exponential (the spotty Notolabrus celidotus: see Jones 1984), asymptotic (the kelp bass Paralabrax clathratus: see Carr 1994a), and threshold (the kelp perch Brachyistius frenatus: see Anderson 1994) - suggests that recruitment increases or remains at a similar density with increasing amount of habitat. The pattern of recruitment exhibited here by the California sheephead demonstrates lower recruitment in habitats with the highest coverage of rock. We suggest that lower recruitment in this instance may have been caused by less suitable habitat. Qualitatively, reefs with a high coverage of habitat appear to also have a more level surface of habitat elevated from the seafloor, with very few open patches of sand or mudstone. Moreover, higher values of rugosity for reefs with the highest coverage of rock appear to be the result of deep, narrow cracks between rocks. Recruits of the California sheephead are commonly located in areas with a protective rock ledge leading to an open habitat, not in holes between rocks or under ledges of rocks; these locations may be more numerous with an intermediate coverage of rock and may be advantageous to the foraging activities or refuge requirements of recruits.

The fact that the blackeye goby had similar densities of recruits in habitats with medium and high coverage 
may indicate that there is no further advantage conveyed by greater amounts of habitat; this probably depends on the magnitude of recruitment. Recruits of the blackeye goby are commonly found in holes between rocks and under ledges of rocks, locations where recruits of the California sheephead do not occur. These types of habitats are more prevalent with increasing coverage of habitat such that the amount of habitat suitable for the blackeye goby should also similarly increase.

Other species on the experimental reef system showed variable relationships between recruitment and coverage of habitat, ranging from no relationship (the señorita) to an exponential relationship (the black surfperch Embiotica jacksonii and the blacksmith Chromis punctipinnis) (T.W.A. et al. unpubl. data). Species-specific responses to coverage of habitat support the idea that heterogeneous landscapes enable a more diverse community structure (Connell 1978, Ogden \& Ebersole 1981, Jones \& Syms 1998).

We have found that the densities of recruits for the California sheephead and the blackeye goby are higher inside a reef than for its ecotone, and other studies have also indicated differences in recruitment between the ecotone and nearby habitats. Jones (1997) documented a 'recruitment shadow' between the perimeter and center of lagoon sites, such that recruitment was higher to perimeter areas, whereas Sweatman \& Robertson (1994) noted lower recruitment to the edges of patch reefs compared to nearby seagrass beds. These studies, respectively, suggest that physical processes and habitat selection in response to reef-based predators may be responsible for the observed patterns of recruitment. The scale of individual reefs in the present study, although large, may not be large enough to detect differences such as those found by Jones (1997), and we did not detect any gradient in the densities of recruits among blocks nor observe a pattern of decreased recruitment to reefs closer to the shore. The density of predators was also highest inside reefs, in contrast to previous observations for some piscivorous fishes (Leaman 1976, Anderson et al. 1989), and contrary to what might be expected if recruits responded to higher predation risk along the ecotone. There is less rock and more sand on the ecotone than inside most of the reefs, and noticeable shifting of sand occurs along the edges of reefs. Thus, differences in the physical characteristics between the ecotone and the inside of reefs may also contribute to the observed distributions of these species.

The effects of ecotones are topical because of increased interest in habitat fragmentation and in how variability in the perimeter-to-area ratio may affect the demography of populations (Temple 1986, Paton 1994, Tewksbury et al. 1998, Hovel \& Lipcius 2001). Because the experimental reefs we employed are standardized in dimension and size, testing for differences in recruitment between the ecotone and the inside of reefs was not confounded by differences in perimeter-toarea ratios.

At the smallest scale, the distribution of the California sheephead and the blackeye goby is explained to some degree by microhabitat associations. The rhosquared values are related to values of $\mathrm{r}^{2}$ used in linear regression, but these values should not be compared directly. Rho-squared values are typically lower than $\mathrm{r}^{2}$, and values between 0.20 and 0.40 should be considered as 'extremely good fits' (Hensher \& Johnson 1981), a range above the values found for these species. However, rugosity was the most important characteristic of microhabitats in predicting the presence of a recruit of either species. The positive relationship between rugosity and the presence of recruits suggests that quadrats with higher rugosity have a higher probability of containing a recruit (Fig. 5). Positive association between rugosity and the presence of recruits agrees with many predator-prey hypotheses, such as (1) more complex habitats may contain a greater number of prey refuges (Hixon \& Beets 1993), or (2) predators may forage less efficiently in more complex or rugose habitats (Beukers \& Jones 1997). Because higher coverages of habitat tend to have higher rugosity values (Table 4, Fig. 5), the probability of the presence of a recruit should also increase correspondingly. Yet, at the scale of entire reefs, the densities of recruits of the California sheephead were higher on reefs of medium habitat coverage. Similar studies have shown that recruits associate with specific habitat characteristics at small spatial scales, but that these habitat char-

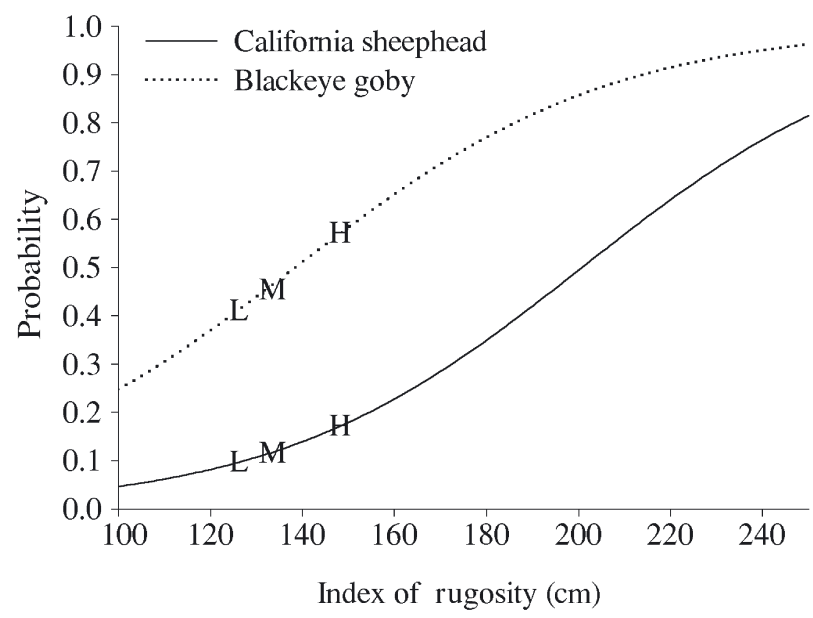

Fig. 5. Semicossyphus pulcher and Rhinogobiops nicholsii. Probability of presence of a recruit as a function of rugosity. Letters denote mean values of rugosity for random quadrats in low (L), medium (M), and high (H) habitat-coverage treatments 
acteristics often do not explain the pattern of recruitment observed among sites (Levin 1991, Tolimieri 1995, Caselle \& Warner 1996). Caselle \& Warner (1996) suggested that recruitment of the bluehead wrasse Thalassoma bifasciatum at an island-wide scale is related to physical oceanographic processes. It is unlikely that oceanographic processes are responsible for the patterns we observed on this experimental reef system, because there were no spatial gradients in recruitment. The presence of recruits may have been associated with higher rugosity at a small scale, but the difference in the densities of recruits among coverages of habitat at a much larger scale might have been the result of other factors associated with the different habitat coverages. More innovative ways with which to measure habitat from smaller to larger scales may help determine specific habitat attributes that are responsible for scale-dependent patterns of recruitment.

\section{Effects of predators}

Predator-induced density-dependent mortality is now commonly found to explain spatial patterns of recruitment in recently settled reef fishes (Hixon \& Carr 1997, Steele 1997b, Forrester \& Steele 2000, Carr et al. 2002). If predators are responsible for patterns of recruitment at this scale, a negative relationship between the density of predators and recruits might be expected (reviewed by Hixon 1991). Predator abundance in our study seldom differed among habitat coverages, suggesting that predator abundance has little effect on the densities of recruits for these species. We are cautious in this interpretation, however, because the timing of predation can produce a variety of positive or negative predator-prey relationships due to an aggregative response of predators and the potential time lags associated with this response (Anderson 2001, Stewart \& Jones 2001); interpretation of the results of our study could depend on when the estimates of abundance were recorded.

\section{Correspondence within a cohort}

The spatial pattern of early recruitment of the California sheephead (October 2001) among the different habitat coverages corresponds with that recorded in later surveys over a $1 \mathrm{yr}$ period. Patterns of abundance appear to have been established very early in the life of the California sheephead on these reefs. The fact that densities of older individuals corresponded to those of recruits generally suggests that recruitment limitation (Doherty \& Fowler 1994) may be stronger than post-settlement density-dependent processes
(Hixon \& Carr 1997, Carr et al. 2002). Recruitment limitation may be more likely when the density of a species is extremely low, whereas density-dependent processes may play a more important role under conditions of relatively dense settlement. Importantly, interpretation of this pattern of correspondence as recruitment limitation is subject to confidence in the initial estimates of early recruitment reflecting larval supply or settlement. We cannot know whether differential mortality did occur shortly after settlement, because post-settlement density-dependent processes may have occurred prior to the first survey in October 2001. For the California sheephead, the October 2001 survey was made within $\sim 1$ mo after initial settlement, while recruits of the blackeye goby, at the same time, may have been up to $\sim 2$ to 3 mo old. Steele (1997b) showed density-independent mortality for recruits of the blackeye goby at densities $<3 \mathrm{~m}^{-2}$; when densities were higher, density-dependent mortality occurred. The densities of recruits of the blackeye goby did not exceed $0.41 \mathrm{~m}^{-2}$ in the present study, and the densities of recruits of California sheephead were much lower. Thus, density-dependent processes seem much less likely to have caused the patterns observed among treatments of habitat coverage for either species.

\section{Conclusions}

We have described the relationship between habitat structure and recruitment of 2 temperate reef fishes at a scale larger than that of most other experimental studies. However, the importance of these habitatdependent relationships to local populations may be relative to the magnitude of recruitment from year to year. At lower densities (as we found for both species on these reefs during the years 2001 and 2002), reef fish populations can be driven more by densityindependent processes (Doherty 1981, 2002, Victor 1983). Therefore, at lower densities, habitat-dependent recruitment may occur and be maintained over time if habitat selection occurs at settlement. Alternatively, at higher densities, post-settlement processes based on refuge availability that cause differential mortality among sites can also generate habitat-dependent relationships. For the California sheephead, recruitment is typically low in this northern part of its range, and recruitment failure does occur in some years (Cowen 1985, this study); however, increased recruitment has been observed during years in which there are El Niño events (Cowen 1985). Therefore, recruitment of the California sheephead along the California coastline may depend largely on habitat selection at settlement at the scale of individual reefs. At a larger spatial scale, however, other processes may be more important to 
overall recruitment (i.e. the recruitment failure of California sheephead in 2002 may have been due to larger oceanographic patterns). This pattern of recruitment failure was also seen in other broadcast spawning species on these experimental reefs as well as across most of the southern California bight (M. Carr pers. comm.). Studies conducted over longer temporal scales with variable recruitment will help to determine the importance of habitat relative to other processes in driving the dynamics of local populations of reef fishes.

Acknowledgements. We thank D. K. Bowker for his more than able diving assistance while working at SCAR, to D. Reed, S. Schroeter, and the UCSB divers for visibility updates and information about the reefs, and to M. Edwards for statistical advice. We also thank the anonymous reviewers for their comments that improved the manuscript. This work was supported in part by the National Sea Grant College Program of the US Department of Commerce's National Oceanic and Atmospheric Administration under NOAA Grant \# NA06RG0142, project \# R/F-188 (to T.W.A.), through the California Sea Grant College Program; and in part by the California State Resources Agency (to T.W.A.). Funding was also provided by the Department of Biology at San Diego State University through the Mabel Myers Scholarship (to K.S.A). The views expressed herein do not necessarily reflect the views of any of these organizations.

\section{LITERATURE CITED}

Almany GR (2004) Differential effects of habitat complexity, predators and competitors on abundance of juvenile and adult coral reef fishes. Oecologia (in press)

Anderson TW (1994) Role of macroalgal structure in the distribution and abundance of a temperate reef fish. Mar Ecol Prog Ser 113:279-290

Anderson TW (2001) Predator responses, prey refuges, and density-dependent mortality of a marine fish. Ecology 82: 245-257

Anderson TW, DeMartini EE, Roberts DA (1989) The relationship between habitat structure, body size and distribution of fishes at a temperate artificial reef. Bull Mar Sci 44: 681-697

Beck MW (1998) Comparison of the measurement and effects of habitat structure on gastropods in rocky intertidal and mangrove habitats. Mar Ecol Prog Ser 169:165-178

Bell SS, McCoy ED, Mushinsky HR (eds) (1991) Habitat structure: the physical arrangement of objects in space. Chapman \& Hall, London

Beukers JS, Jones GP (1997) Habitat complexity modifies the impact of piscivores on a coral reef fish population. Oecologia 114:50-59

Booth DJ (1992) Larval settlement patterns and preference by domino damselfish Dascyllus albisella Gill. J Exp Mar Biol Ecol 155:85-104

Brown AF, Stillman RA (1993) Bird-habitat associations in the eastern Highlands of Scotland. J Appl Ecol 30:31-42

Caley MJ, Carr MH, Hixon MA, Hughes TP, Jones GP, Menge BA (1996) Recruitment and the local dynamics of open marine populations. Annu Rev Ecol Syst 27:477-500

Carr MH (1991) Habitat selection and recruitment of an assemblage of temperate reef fishes. J Exp Mar Biol Ecol 146:113-137
Carr MH (1994a) Effects of macroalgal dynamics on recruitment of a temperate reef fish. Ecology 75:1320-1333

Carr MH (1994b) Predicting recruitment of temperate reef fishes in response to changes in macrophyte density caused by disturbance. In: Stouder DJ, Fresh KL, Feller RJ (eds) Theory and application in fish feeding ecology. University of South Carolina Press, Columbia, p 255-269

Carr MH, Anderson TW, Hixon MA (2002) Biodiversity, population regulation, and the stability of coral-reef fish communities. Proc Natl Acad Sci USA 99:11241-11245

Caselle JE, Warner RR (1996) Variability in recruitment of coral reef fishes: the importance of habitat at two spatial scales. Ecology 77:2488-2504

Chatterjee S, Hadi AS, Price B (2000) Regression analysis by example, 3rd edn. John Wiley \& Sons, New York

Connell JH (1978) Diversity in tropical rainforests and coral reefs. Science 199:1302-1310

Cowen RK (1985) Large scale pattern of recruitment by the labrid Semicossyphus pulcher: causes and implications. J Mar Res 43:719-742

Cowen RK (1991) Variation in the planktonic larval duration of the temperate wrasse Semicossyphus pulcher. Mar Ecol Prog Ser 69:9-15

Cowen RK (2002) Larval dispersal and retention and consequences for population connectivity. In: Sale PF (ed) Coral reef fishes: dynamics and diversity in a complex ecosystem. Academic Press, San Diego, p 149-170

Dethier MN, Graham ES, Cohen S, Tear LM (1993) Visual versus random-point percent cover estimations: 'objective' is not always better. Mar Ecol Prog Ser 96:93-100

Doherty PJ (1981) Coral reef fishes: recruitment-limited assemblages? Proc 4th Int Coral Reef Symp 2:465-470

Doherty PJ (2002) Variable replenishment and the dynamics of reef fish populations. In: Sale PF (ed) Coral reef fishes: dynamics and diversity in a complex ecosystem. Academic Press, San Diego, p 327-355

Doherty PJ, Fowler AJ (1994) An empirical test of recruitment limitation in a coral reef fish. Science 263:935-939

Forrester GE, Steele MA (2000) Variation in the presence and cause of density-dependent mortality in three species of reef fishes. Ecology 81:2416-2427

Friedlander AM, Parrish JD (1998) Habitat characteristics affecting fish assemblages on a Hawaiian coral reef. J Exp Mar Biol Ecol 224:1-30

Graham MH (1997) Factors determining the upper limit of giant kelp Macrocystis pyrifera Agardh along the Monterey peninsula, central California, USA. J Exp Mar Biol Ecol 218:127-149

Gutierrez L (1998) Habitat selection by recruits establishes local patterns of adult distribution in two species of damselfishes: Stegastes dorsopunicans and S. planifrons. Oecologia 115:268-277

Hensher D, Johnson LW (1981) Applied discrete choice modeling. Croom Helm, London

Hixon MA (1991) Predation as a process structuring coral reef fish communities. In: Sale PF (ed) The ecology of fishes on coral reefs. Academic Press, San Diego, p 475-508

Hixon MA, Beets JP (1993) Predation, prey refuges, and the structure of coral-reef fish assemblages. Ecol Monogr 63: 77-101

Hixon MA, Carr MH (1997) Synergistic predation, density dependence, and population regulation in marine fish. Science 277:946-949

Holbrook SJ, Schmitt RJ (1997) Settlement patterns and process in a coral reef damselfish: in situ nocturnal observations using infrared video. Proc 8th Int Coral Reef Symp 2: $1143-1148$ 
Holbrook SJ, Forrester GE, Schmitt RJ (2000) Spatial patterns in abundance of a damselfish reflects availability of suitable habitat. Oecologia 122:109-120

Hovel KA, Lipcius RN (2001) Habitat fragmentation in a seagrass landscape: patch size and complexity control blue crab survival. Ecology 82:1814-1829

Jones GP (1984) Population ecology of the temperate reef fish Pseudolabrus celidotus Block and Schneider (Pisces: Labridae). I. Factors influencing recruitment. J Exp Mar Biol Ecol 75:257-276

Jones GP (1991) Post-recruitment processes in the ecology of coral reef fish populations: a multifactorial perspective. In: Sale PF (ed) The ecology of fishes on coral reefs. Academic Press, San Diego, p 294-328

Jones GP (1997) Relationships between recruitment and postrecruitment processes in lagoonal populations of two coral reef fishes. J Exp Mar Biol Ecol 213:231-246

Jones GP, Syms C (1995) Influence of disturbance and habitat degradation on coral reef fish communities. In: Jones GP, Doherty PJ, Mapstone BD, Howlett L (eds) ReeFish '95: recruitment and population dynamics of coral reef fishes. CRC Reef Research Centre, Townsville, Australia

Jones GP, Syms C (1998) Disturbance, habitat structure and the ecology of fishes on coral reefs. Aust J Ecol 23:287-297

Keough MJ, Downes BJ (1982) Recruitment of marine invertebrates: the role of active larval choices and early mortality. Oecologia 54:348-352

Leaman BM (1976) The ecology of fishes in British Columbia kelp beds. I. Barkley Sound Nereocystis beds. Fisheries Development Rep 22. Marine Resources Branch, Ministry of Environment, British Columbia

Levin PS (1991) Effects of microhabitat on recruitment variation in a temperate reef fish. Mar Ecol Prog Ser 75: 183-189

Levin PS (1993) Habitat structure, conspecifics presence and spatial variation in the recruitment of a temperate reef fish. Oecologia 94:176-185

Levin PS (1994) Small-scale recruitment variation in a temperate fish: the roles of macrophytes and food supply. Environ Biol Fish 40:271-281

Levin PS, Petrik R, Malone J (1997) Interactive effects of habitat selection, food supply and predation on recruitment of an estuarine fish. Oecologia 112:55-63

MacArthur RH, MacArthur J (1961) On bird species diversity. Ecology 42:594-598

MacFaden SW, Capen DE (2002) Avian habitat relationships at multiple scales in a New England forest. For Sci 48: 243-253

Maurer BA (1985) Avian community dynamics in desert grassland: observational scale and hierarchical structure. Ecol Monogr 55:295-312

Meekan MG, Milicich MJ, Doherty PJ (1993) Larval production drives temporal patterns of larval supply and recruitment of a coral reef damselfish. Mar Ecol Prog Ser 93: $217-225$

Milicich MJ, Meekan MG, Doherty PJ (1992) Larval supply: a good predictor of recruitment of three species of reef fish (Pomacentridae). Mar Ecol Prog Ser 86:153-166

Miller DJ, Lea RN (1972) Guide to the coastal marine fishes of California. Fish Bull Calif 157:168

Nelson WG (1979) Experimental studies of selective predation on amphipods: consequences for amphipod distribution and abundance. J Exp Mar Biol Ecol 38:225-245

Nemeth RS (1998) The effect of natural variation in substrate architecture on the survival of juvenile bicolor damselfish. Environ Biol Fish 53:129-141

Ogden JC, Ebersole JB (1981) Scale and community structure of coral reef fishes: a long-term study of a large artificial reef. Mar Ecol Prog Ser 4:97-103

Paton PWC (1994) The effect of edge on avian nest success: how strong is the evidence? Conserv Biol 8:17-26

Petrik R, Levin PS, Stunz GW, Malone J (1999) Recruitment of Atlantic croaker Micropogonias undulatus: do postsettlement processes disrupt or reinforce initial patterns of settlement? Fish Bull US 97:954-961

Pianka ER (1966) Convexity, desert lizards, and spatial heterogeneity. Ecology 47:1055-1059

Reagan DP (1991) The response of anolis lizards to hurricaneinduced habitat changes in a Puerto Rican rain forest. Biotropica 23:468-474

Risk MJ (1972) Fish diversity on a coral reef in the Virgin Islands. Atoll Res Bull 153:1-6

Roberts CM, Ormond RFG (1987) Habitat complexity and coral reef fish diversity and abundance on Red Sea fringing reefs. Mar Ecol Prog Ser 41:1-8

Rotenberry JT, Wiens JA (1998) Foraging patch selection by shrub-steppe sparrows. Ecology 79:1160-1173

Sale PF (1991) Habitat structure and recruitment in coral reef fishes. In: Bell SS, McCoy ED, Mushinsky HR (eds) Habitat structure: the physical arrangement of objects in space. Chapman \& Hall, London, p 197-210

Schmitt RJ, Holbrook SJ (1999) Mortality of juvenile damselfish: implications for assessing processes that determine abundance. Ecology 80:35-50

Schmitt RJ, Holbrook SJ (2000) Habitat-limited recruitment of coral reef damselfish. Ecology 81:3479-3494

Sherry TW, Holmes RT (1985) Dispersion patterns and habitat responses of birds in northern hardwood forests. In: Cody ML (ed) Habitat selection in birds. Academic Press, New York, p 283-309

Steele MA (1995) The contributions of predation, competition, and recruitment to the population regulation of two temperate reef fishes. PhD thesis, University of California, Santa Barbara

Steele MA (1997a) The relative importance of processes affecting recruitment of two temperate reef fishes. Ecology 129-145

Steele MA (1997b) Population regulation by post-settlement mortality in two temperate reef fishes. Oecologia 112: $64-74$

Steele MA (1998) The relative importance of predation and competition in two reef fishes. Oecologia 115:222-232

Steele MA (1999) Effects of shelter and predators on reef fishes. J Exp Mar Biol Ecol 233:65-79

Steele MA, Forrester GE, Almany GR (1998) Influences of predators and conspecifics on recruitment of a tropical and a temperate reef fish. Mar Ecol Prog Ser 172: 115-125

Stewart BD, Jones GP (2001) Associations between the abundance of piscivorous fishes and their prey on coral reefs: implications for prey-fish mortality. Mar Biol 138: 383-397

Sweatman HPA (1985) The influence of adults of some coral reef fishes on larval recruitment. Ecol Monogr 55:469-485

Sweatman HPA, Robertson DR (1994) Grazing halos and predation on juvenile Caribbean surgeonfishes. Mar Ecol Prog Ser 111:1-6

SYSTAT (2000) SYSTAT 10.0 for Windows. SPSS, Evanston

Temple SA (1986) Predicting impacts of habitat fragmentation on forest birds: a comparison of two models. In: Verner J, Morrison ML, Ralph CJ (eds) Wildlife 2000: modeling habitat relationships of terrestrial vertebrates. University of Wisconsin Press, Madison, p 301-304

Tewksbury JJ, Heil SJ, Martin TE (1998) Breeding produc- 
tivity does not decline with increasing fragmentation in a western landscape. Ecology 79:2890-2903

Tolimieri N (1995) Effects of microhabitat characteristics on the settlement and recruitment of a coral reef fish at two spatial scales. Oecologia 102:52-63

Tolimieri N (1998) The relationship among microhabitat characteristics, recruitment and adult abundance in the stoplight parrotfish Sparisoma viride at three spatial scales. Bull Mar Sci 62:253-268

Tupper M, Boutilier RG (1997) Effects of habitat on settlement, growth, predation risk and survival of a temperate reef fish. Mar Ecol Prog Ser 151:225-236

Victor BC (1983) Recruitment and population dynamics of a coral reef fish. Science 219:419-420

Warner RR (1975) The reproductive biology of the proto-

Editorial responsibility: Otto Kinne (Editor),

Oldendorf/Luhe, Germany gynous hermaphrodite Pimelometopon pulchrum (Pisces: Labridae). Fish Bull US 73:262-283

Weins JA (1985) Habitat selection in variable environments: shrub-steppe birds. In: Cody ML (ed) Habitat selection in birds. Academic Press, New York, p 227-251

Weins JA (1989) Spatial scaling in ecology. Funct Ecol 3: 385-397

Wiley JW (1973) Life history of the western North American goby Coryphopterus nicholsii (Bean). Trans S Diego Soc Nat Hist 17:187-208

Williams SE, Marsh H, Winter J (2002) Spatial scale, species diversity, and habitat structure: small mammals in Australian tropical rain forest. Ecology 83:1317-1329

Zar JH (1999) Biostatistical analysis, 4th edn. Prentice Hall, Upper Saddle River, NJ

Submitted: April 25, 2003; Accepted: March 16, 2004

Proofs received from author(s): July 27, 2004 